\title{
IT, Ethics and Education : Teaching the Teachers (and their Pupils)
}

\author{
Bern Martens \\ Lecturer in Information Technology \\ Teacher Training Department \\ Catholic University College Leuven (KHLeuven - Belgium) \\ Bern.Martens@khleuven.be
}

\begin{abstract}
At colleges and universities, computer ethics has established itself as an integral part of computer science and information technology programmes, at least in principle. However, many of the issues involved are not only relevant to IT professionals, but also to IT users or even any citizens of our IT intensive society. It is therefore important that ethical issues in IT receive proper attention in secondary school, both in IT classes and other contexts. For this to be possible, firstly, educational policy and plans have to be adjusted. Secondly, teachers must get a thorough introduction to computer ethics, and learn appropriate teaching methods. Finally, teaching materials have to be developed and distributed. We describe ongoing efforts to help bring all this about.
\end{abstract}

Keywords: computer ethics, teacher training, IT education, IT curriculum, secondary school

\section{Introduction and motivation}

At colleges and universities, computer ethics has established itself as an integral part of computer science and information technology programmes [Johnson, 2001, Bynum \& Rogerson, 2004, Barroso \& Melara, 2004, ACM, 2005], at least in principle. However, little attention has been devoted to computer ethics 
at secondary school level and in teacher training.In this paper, we argue that computer ethics should be incorporated in the secondary school information technology curriculum. We distinguish three major reasons for doing so.

First, awareness of the major ethical, social and legal issues in information technology (IT) promotes a more considerate attitude towards (the use of this technology in both expert and lay users. The need to include computer ethics in college and university IT curricula is (therefore) well established [ACM, 2005]. But vocational high school also offers specialised IT curricula, and the arguments in favour of computer ethics at college and university level apply virtually unchanged in that context. Moreover, many youngsters who never enroll in a specialised IT programme, nowadays acquire considerable IT competences in e.g. webdesign, online information retrieval and communication, multimedia manipulation, etc. [RISCP, 2006]. Such skills can easily be used to harm others (or themselves), and computer ethics classes in school can and should contribute towards preventing this. Secondly, insight into the ethical and social dimensions of information technology enhances a well-founded self-reliance in (future) citizens of our IT-based society. Surely, we must attempt to raise the ethical standards in cyberspace by teaching computer ethics to the expert few. However, it will also be very productive to promote a good awareness of the major issues among the vast majority of lay users, including a structural knowledge of their ethical and legal rights and duties as well as technical and/or procedural competences that will enable them to reduce the risks they are exposed to. Thirdly, in a broader educational perspective, computer ethics offers excellent opportunities to introduce secondary school pupils to philosophy and ethics in an area which many of them, once "discovered", perceive as highly personally relevant.

The remainder of this paper is structured as follows. In Section 2, we first briefly sketch the content and educational approach in the IT courses currently included in the Flemish secondary school curriculum. We point out some major deficiencies, and move on to describe recent efforts in policy making, proposing a new, coherent vision on IT education throughout secondary school. We also indicate the need(s) for computer ethics in the latter context. Subsequently, in Section 3, we address in more detail the issue of teaching computer ethics in the (improved) secondary school IT curriculum. We investigate what should be taught at which age, and draw on experience gained from several years of small scale experiments to suggest some methodological guidelines. Section 4 then looks at computer ethics in teacher training. We describe our approach and experiences with seminars and student projects over the last seven years, and our efforts to support computer ethics classes in secondary school. Finally, in Section 5, we volunteer some conclusions and outline plans for further work.

Throughout this paper, with only a few exceptions, we focus on courses which take information technology itself as a study subject. Other contexts also offer opportunities to address issues in computer ethics. However, in this paper, we wish to concentrate on IT classes taught by IT teachers, and the specific opportunities and challenges in those settings. Also, we only discuss teaching computer ethics (and related subjects) to pupils, ignoring the ethical and safety issues in using IT at school [Martens, 2003a], as well as the ethical issues connected with using IT as an educational tool [Cohen, 2000, Jefferies \& Stahl, 2005]. 
(and their Pupils)

Finally, we note that an earlier version of this paper appeared as [Martens, 2005].

\section{Information technology and computer ethics in the (Flemish) secondary school curriculum}

Currently, little time is spent on computer ethics in (most) Flemish secondary school IT classes and courses. In the next section, we investigate how this should and can be changed. But first, we take a look at the educational context in which computer ethics must find its place: which are the main IT courses and study programmes currently featuring in the Flemish secondary education curriculum and what is their content? And what may we expect or hope for the near future, especially with respect to computer ethics? We shall limit our brief description to the situation in the Catholic school network, for it attracts about $70 \%$ of the Flemish secondary school pupils. Moreover, in the other major networks, the situation of IT as a study subject is quite similar.

\subsection{The current situation}

Flemish secondary education is divided in three grades of two years each: first grade from 12 to 14 , second grade from 14 to 16 , and third grade from 16 to 18 years of age. Currently, IT as a study subject features as follows in this setting. First, some study programmes with a professional profile in second and (mainly) third grade (of vocational school) specialise in IT, offering it at a volume of up to 10 hours of class a week. They aim at preparing pupils for the labour market as IT professionals, and/or serve as a preamble to college studies in IT. Secondly, in some schools, pupils with (mainly) mathematical-scientific study profiles in general (non vocational) education can choose up to 2 hours of IT a week in third grade. Most of these courses focus on problem analysis and programming. Thirdly, (nearly) all pupils are taught IT in second grade as a two-year course, with one hour of class a week. This course is meant as a general introduction to IT and its use. Finally, for a few years now, pupils are expected to acquire a number of basic IT competences in first grade. Many (but not most) schools therefore offer one weekly hour of IT to their first year pupils.

So, currently, for most pupils, the course in second grade is their main IT course in secondary school; for many, it is the only one. It comprises about 50 hours of class, to be devoted to the use of computers, operating systems, communication facilities and applications software, as well as introductions to hardware and networks, problem analysis and programming, and ethics [VVKSO, 2003]. The course objectives also state that applications software classes should emphasise taskoriented problem-solving, rather than exhaustive program manipulation skills. However, this course has been suffering from many problems. In practice, often pupils were mainly expected to learn Word and Excel by mostly imitating sequences of actions from the teacher or the textbook. In 2002, the situation deteriorated further because societal pressure led to the inclusion of the European Computer Driving Licence [ECDLF, 2006] objectives in the course goals. These objectives are numerous, and very much geared towards immediate practical applicability in 
(mainly) office applications. As a consequence, the time available to introduce pupils to aspects of IT such as hardware, network structure, programming and ethics was severely reduced. Nor have the teaching methods in application software classes benefited from the increased time pressure. If we use the terminology of [ACM, 2003], we must conclude that the classroom emphasis has shifted further towards IT literacy, the course goals (still) largely focus on IT fluency but their achievement has remained as elusive as before for many or even most teachers and pupils, and core computer science goals as well as content have (nearly) shrunk to the point of disappearance.

\subsection{A vision for the future}

It is always darkest before dawn. The development described above almost proverbially sparked a counter movement. An outspoken contribution was made by [Martens, 2003b] which proposed to shift gradually the focus of attention in secondary school IT courses, starting with IT use in first grade, continuing with understanding IT in second grade, and learning to produce (and/or maintain) IT in third grade. Very important was the formation of a thinktank with IT education experts, selected from secondary schools, central IT coordination at the school network level, and teacher training, to develop a coherent vision on IT education at the secondary school level. After two years of work, this group delivered a report [VVKSO, 2005], partially based on [Martens, 2003b], advising policy makers on the essential lines of development of a coherent secondary school IT curriculum from first to third grade. A detailed discussion of the ideas put forward in [Martens, 2003b] and [VVKSO, 2005] is outside the scope of this paper, but we do take a closer look at some elements which are particularly relevant to our present purpose.

In [VVKSO, 2005], it is proposed that all pupils have (at least) one weekly hour of IT throughout first and second grade. This should provide sufficient time to learn to use and understand IT at a level suitable for the pupil's study profile. Moreover, one of the areas of basic IT competences which all pupils must acquire according to [VVKSO, 2005] reads as follows: "Elementary social and ethical competences, including those related to privacy, copyright and environmental aspects".

Perhaps even more important is the conceptual shift to understanding IT as the main overall goal in the second grade course.

Obviously, such an understanding cannot be achieved without a substantial computer ethics component. Indeed, [ACM, 2003] proposes a similar focus of attention in its intended (in our terminology) second grade course "Computer Science in the Modern World". The main goal of that course should be: "to provide all students with an introduction to the principles of computer science and its place in the modern world". As one of ten main topics of interest in the proposed course, [ACM, 2003] lists: "Ethical issues that relate to computers and networks (including security, privacy, intellectual property, the benefits and drawbacks of public domain software, and the reliability of information on the Internet), and the positive and negative impact of technology on human culture".

Finally, in third grade, not only some pupils with specialised vocational profiles should study advanced IT, but many other pupils should have the possibility to 
include an optional advanced IT course in their programme. IT ethics (professional as well as lay) must be an integral part of such courses.

\section{Teaching computer ethics in secondary school}

Dawson and Newman [Dawson \& Newman, 2002] described an approach to (professional) IT education where empowerment is the central concept. The essence of their approach is as follows: rather than emphasising particular, readily usable, technical competences, the ability to learn through and from exploration, possibly failure, is the central course goal. In this way, students "develop skills and confidences so that they can acquire the necessary expertise (in a specific field) when they need it". This approach seems very valuable for teaching IT fluency and (an introduction to) computer science in secondary school in general, as well as ethical competences in particular. It also fits in well with the shift in attention from IT use in first grade, via IT understanding in second grade to IT production in third grade.

In the remainder of this section, we take a closer look at the three grades in secondary school, outline the main topics in computer ethics which should be treated in each one, and venture some methodological guidelines for doing so. Where possible, we draw upon experience in teaching ethics by teacher training students over the past few years. Throughout the discussion, empowerment of the pupils in IT and computer ethics will be the central guiding concept.

\subsection{First grade (age 12-14)}

In this grade, the focus of the IT curriculum is on learning to use common IT in a systematic and structured way. With respect to computer ethics, this implies emphasising elementary aspects of online ethics and safety. Most pupils at this age are intellectually not sufficiently mature to learn about or discuss general ethical issues in IT. On the other hand, they have to be made aware of the risks and/or inconveniences implied for themselves and/or others by unsafe and/or improper use of IT. To give an example, most pupils at this age no longer need to be taught how to send an e-mail, but it does prove necessary to teach them which kind of language use is suitable in which kind of contexts, and why. Subjects such as privacy, copyright and computer crime should also be addressed, but always in very practical contexts of immediate personal relevance to the pupils. Obvious topics include safe chatting behaviour, the legal risks connected to illegal downloading, a cautious attitude towards possible virus infection, and many more.The best overall teaching approach to achieve this kind of objectives lies probably in relatively short explicit interventions by the teacher (or the textbook), anytime it seems appropriate to do so in the light of the "technical" subject matter at hand. In this way, pupils will, to some extent, learn to systematically incorporate important aspects of ethics and safety in their IT use. Of course, occasionally entire classes can be devoted to these subjects. Even organising or improvising somewhat extensive group discussions can be appropriate, especially when pupils themselves raise relevant issues on their own initiative.

Since IT as an explicit subject in the first grade is a relatively new and still quite rare phenomenon in Flemish secondary schools, our experience with teaching ethics at this level has been limited. One student recently tried to set up a whole hour 
classroom discussion on privacy in a second year class group with a vocational profile and utterly failed: her pupils maintained that they needed no privacy, so what was all the fuss about? Another student successfully devoted an entire hour of class with first year pupils to chatting and password safety, while a third experimented extensively and equally successfully (in a Dutch first year class group) with an approach like the one described in the previous paragraph.

\subsection{Second grade (age 14-16)}

Understanding IT cannot be achieved by (only) using it. At the age of 14 or 15, most pupils attain a level of maturity which allows teachers to address more general ethical and social issues relating to information technology. Therefore, computer ethics sessions and projects should be a substantial part of the second grade IT curriculum.

In this context, teaching for empowerment can have a double meaning. First, pupils will feel empowered, not only through gaining technical insight and user confidence, but also by discovering some of the more subtle aspects of computer ethics and safety. At this age, for many pupils, privacy does become an important issue, and an investigation into online privacy and the many ways in which it can be undermined becomes interesting. Topics of a more general nature become feasible. A discussion of open and free software and the philosophy behind it can be of interest, especially when combined with the pupils' own first steps in programming. The latter context is also suitable for a more profound reflection on copyright, since they are likely to discover in person how much effort it takes to produce correct and usable programs. This list is far from complete, but there is a second point to be made. Indeed, at this age, pupils develop sufficient intellectual maturity for the kind of reasoning through analogy which lies at the heart of computer ethics. Cases on illegal copying of music can now be made through analogies with e.g. furtive homework copying. Most pupils experience such aspects in IT as very relevant to their own pursuits and will be interested. This area therefore offers excellent opportunities to stimulate the pupils' capacity for logical, philosophical analysis and analogical reasoning. This in turn leads to a considerable boost in empowerment.

In both areas, to get good results, it is crucial that computer ethics teaching is not reduced to the teacher (or the textbook) reciting a list of do's and don'ts. The pupils' core activity must lie in their own reflection and discussion. If there is sufficient time available, it is recommended that they should (also) perform projects, not unlike the ones that will be described in the section on teacher training below (see Section 4). As an added benefit, such projects emphasise the fact that the key factor to understanding IT and achieving IT fluency is not hammering away at a keyboard.

Experiments by teacher training students show that age and technical IT competence must be taken into account when choosing teaching approaches for computer ethics topics in second grade. In many ways, pupils in the first year of this grade are still too young and (currently) too ignorant in the area of IT to enable a profound and prolongued treatment of computer ethics issues. It can therefore be a good idea to (just) stimulate their awareness of the issues through e.g. the collection of newspaper cuttings and/or the execution of short research projects at "empty" 
moments. One student suggested putting a box with questions in the classroom and having pupils, on completion of their technical tasks, select one question for internet research during the remainder of the class. Subsequently, at some time, compiled results can be presented to the rest of the class and/or the teacher.

In the second year of the second grade, dedicated computer ethics classes have definitely proved feasible. In inexperienced groups who still feel relatively insecure about IT, an element of game or contest can be a good idea (an example can be found online at [Martens, 2001]). In a class group with a high level of IT expertise, a two hour version of the quite profound session for last year pupils described below in Section 3.3 , proved very succesful.

\subsection{Third grade (age 16-18)}

Many of the above considerations about understanding IT, teaching for empowerment and computer ethics in second grade, also hold for third grade. Of any third grade courses aiming at IT fluency, computer ethics must therefore be an integral part.

However, since the emphasis in IT courses of many third grade study profiles will be on IT production and computer science, professional IT ethics and responsibilities also become relevant. In such courses, pupils should perhaps already be introduced to professional codes of conduct, and be invited to reflect on the importance of such codes, both for society in general as well as for themselves as an IT professional in the bud. Somewhat less ambitiously, pupils in specialised IT profiles in secondary school are often those among their peers (and even teachers) with the most developed IT and multimedia competences. This gives them considerable power over more naive users, and it is important that they learn to handle this power in an ethically correct way.

Our experience with ethics sessions in third grade classes with a professional IT profile has been almost undividedly positive. Pupils prove themselves to be very eager learners indeed, provided the teaching approach creates sufficient room for their active participation. One example is a four hour session [Bannier \& Onkelinx, 2005 ] led by two teacher training students for a group of about 20 pupils in the final year of an IT oriented study programme. The pupils had been informed beforehand that there would be a whole morning devoted to computer ethics. They told us afterwards that they had expected four hours of utter boredom. Instead, they were asked to perform small group projects using internet, newspaper cuttings and video fragments on issues related to privacy, copyright, computer crime and (mis)use of information on the internet. The work on these projects was interlaced with plenary discussions and some short games and quizzes. Many pupils found the session a veritable eye-opener provoking reflection on aspects of IT and their use of it they had never before given any serious consideration. Happy as we may be with that result, it is of course sad that they had to wait for this to happen until the final months of their six years in secondary school ... 


\section{Educating the educators: computer ethics in teacher training}

Experiments by teacher training students over the last few years showed that most pupils in second grade are willing and indeed eager to discuss topics such as online privacy, illegal copying, unethical web content, and even more "technical" ones such as open software, spyware and hacker ethics. Likewise, there were very positive reactions from (future) "IT specialists" in third grade, whenever students were invited to do sessions in that context. Pupils repeatedly contacted students up to weeks or months afterwards to comment on how stimulating they found the sessions, and/or ask for further information.

If pupils respond so enthusiastically, then why is there so little computer ethics in most IT courses in secondary school? One of the reasons is that the course outlines are overstuffed with "useful" subjects. Another important factor is the lack of competent teachers. It is crucial that IT teachers in their initial training get an extensive introduction to computer ethics, and those who move into the field "sideways" (without having had a formal training in IT and/or its teaching) should not only brush up on their "technical" knowledge.

The study programme for secondary school IT teachers at the Catholic University College Leuven features a (compulsary) seminar series on computer ethics for its last year students. The central goal of the course is to make the students see the relevance and importance of computer ethics, in society in general and in secondary school IT classes in particular, and to provoke a willingness or even eagerness to properly include computer ethics in their own (later) teaching practice, in spite of an almost total lack of readily available teaching materials, tried and tested educational approaches, and/or colleagues experienced in this field. However, the available time for group sessions is limited to six two hour sessions, and the average student workload for the course is set at about 40 hours.

To select an effective educational approach within these rather severe constraints, some important aspects had to be taken into account. First, teacher training at this educational level has a professional rather than an academic profile. Choosing mainly academic study and paper production as the core student activity [Thompson \& Edwards, 2004] was therefore considered inappropriate. Secondly, the context for the course is teacher training, albeit in IT, not the formation of computing experts. Therefore, the focus cannot be on codes of conduct for IT professionals [Stahl et al., 2004]. On the other hand, we are dealing with students in their third and final year of teacher training who have already acquired a considerable degree of technical and educational proficiency in the previous two years, but most of whom have only a scant knowledge of computer ethics issues. All these considerations led to an approach which aims at student activity with a high degree of educational experiment on an adequate foundation of subject knowledge. Students are required to read an introductory textbook on computer ethics [Martens, 2000] which serves as a basis for further work and discussions. However, since the main goal of the course lies in changing attitudes rather than acquiring knowledge, the brunt of the students' workload is on projects they carry out in small groups, investigating a particular topic or field within computer ethics and (its) teaching. For these projects, students are specifically asked to (mainly) act [Martens, 2004]. They e.g. interview 
supermarket managers on their store's privacy policy, contact computer hackers to discuss their acts and ethics, investigate downloading of music and software among fellow students and/or pupils in secondary school, speak with school principals about the ethical aspects of their school's IT policy, etc. On completion, the project results are presented by the project group members to the entire classgroup, including the teacher, during one of the seminars while experimenting as much as is feasible and functional with teaching media and methods: newspaper cuttings, TV-programme or movie fragments, video reports they themselves made, tables, graphs and presentations, internet, role playing, quizzes, games, and discussions, to name just a few. The results are often astounding: many project groups are extremely creative, and often (but not always) the information gathered is highly relevant and a good complement to and/or illustration of the textbook.

To our knowledge, no other published approach to teaching computer ethics puts this much stress on acting, communicating and experimenting, rather than gathering, processing and discussing information and views. The drawback of this approach is a certain lack of conceptual penetration. However, for students with the above sketched profile, it is highly effective: student evaluations of the course are very positive, and many students try their hand at computer ethics classes during their teaching practice and include computer ethics in their own subsequent independent teaching.

It has been mentioned repeatedly: teachers who aspire at devoting serious attention to computer ethics in their IT classes in secondary school, will find virtually no specific teaching materials. Many IT textbooks for secondary school throw only a few cursory glances at ethics, and none that we know of comes even near to a sufficiently profound treatment. Therefore, in a long term effort to support and improve computer ethics teaching in secondary school, teaching materials developed by students in teacher training, either for their teaching practice, or in more extensive, focussed undergraduate projects are made available on the web [Martens, 2001] for general use under a suitable creative commons license [CC, 2006].

During the last few years, we also had the opportunity to do a computer ethics course with a mixed group of students from all over Europe in the fields of business, IT and (mostly non-IT) teacher training [Dierick \& Martens, 2006]. The course comprises lectures by the teachers, guided project group sessions (also online) and student project presentations. Apart from the IT students, virtually none of the students involved has much technical knowledge of IT, often not even a good operational one. Nevertheless, an overwhelming majority of the participating students from any field of study (with the noteworthy exception of kindergarten teacher training) rates the course as very interesting and professionally relevant. Obviously, even among non specialists, computer ethics (and IT empowerment) is in high demand.

\section{Conclusions, ongoing and further work}

A lot of work remains to be done. First, teaching experiments by teacher training students will be continued. Over the next few years, we want to considerably extend 
the assortment of teaching materials available at [Martens, 2001], aiming at covering a broad range of topics, educational approaches, age groups and study profiles.

At the time of writing, we are investigating the possibilities for cooperation in the field of computer ethics across various subjects in secondary school. Specifically, a student with (Dutch, history and) English as teaching subject(s) is executing a project on computer ethics teaching in English classes in Flemish schools. First experiments delivered encouraging results. Since the student herself has little or no specialised IT knowledge, this project is also providing interesting insights with respect to the amount of technical background required for such an undertaking, and sheds light on the need for and/or the possibilities created by team teaching in computer ethics across subject boundaries. Somewhat related are ongoing experiments with seminars on IT and ethics for students in Dutch aimed at providing them with the necessary background for treating IT subjects incorporated in first grade mother tongue classes.

It would be very interesting to more systematically investigate the (long as well as short term) effects computer ethics classes have on the knowledge, capacities and attitudes of pupils in (and after) secondary school. Experience has shown that these are likely to differ according to age, study profile and teaching approach. However, designing, executing and processing large scale scientific research of this nature is beyond the means of a teacher training institute. A close cooperation with a research institute or university, as well as some secondary schools, therefore seems to be in order.

Next, good educational policies and programmes remain an important issue. While [VVKSO, 2005] lays a foundation for an improved IT curriculum in secondary school, it does only that. At the time this paper is being written, it remains to be seen which of these expert recommendations will finally find their way into the curriculum tables. Getting extra hours of class for IT implies reducing the hours of class for one or more other subjects, and this is politically very sensitive. It is therefore deplorable but not surprising that a recent first official reaction by the highest educational policy committee in the Flemish Catholic secondary school network, though overall rather encouraging, rejected the proposal to introduce an obligatory IT course for all pupils in first grade of secondary school. Even within the available IT hours, computer ethics will not (and should not) be the main subject. How much of the available time it will be explicitly allotted will no doubt be a matter of discussion. Luckily, societal pressure to broaden IT teaching so as to include structurally both social and ethical issues is increasing. In the ongoing public debate on illegal downloading and copying of music e.g., some recent contributors (finally) voiced the opinion that raising ethical awareness through proper education might be more effective than the (remote) chance of getting caught and severely punished. Also, the growing amount of complaints about cyber bullying among children and teenagers have led to concerned questions in the Flemish parliament. As a result, a research project directed by the Flemish Institute for Assessment of Science and Technology (viWTA) has investigated the problem, and one of the resulting policy suggestions is likely to be a recommendation to devote more attention to social and ethical issues in secondary school IT classes.

Good computer ethics education is impossible without well educated teachers. Currently, apart from some isolated initiatives, the curricular status of computer 
ethics in Flemish IT study programmes at colleges and universities, including most IT teacher training programmes, is as bad (or even worse) as it is in secondary school. This is in stark contrast with the ACM recommendations [ACM, 2005], which are much more closely inspected as well as respected for any aspects of a more technical nature. It is beyond the scope of this paper to analyse the reasons for this sad state of affairs, but it will be absolutely obvious that any structural improvement in secondary school computer ethics teaching must involve teacher training, both pre-service as well as in-service. Moreover, using IT in an ethically, professionally and legally correct as well as socially and environmentally responsible way cannot be taught by IT teachers alone. Teachers (in subjects other than IT) should not only be functionally but also ethically competent in IT, and they should devote appropriate attention to computer ethics (in a broad sense) in their own teaching. Personal teaching experience in both of these areas indicates that most students in teacher training, be it specifically for IT or not, show great interest and enthousiasm when confronted with topics in computer ethics. So, the main problem in this field currently seems to lie with many of the teachers' teachers.

Throughout this paper, the focus of attention has been on IT ethics and to some extent safety, with only a few excursions into the broader field that has recently been termed "social informatics" [Kling et al., 2005] and defined as follows: "Social Informatics refers to the interdisciplinary study of the design, uses, and consequences of ICTs that takes into account their interaction with institutional and cultural contexts". It is eloquently argued [Kling et al., 2005] that the growing body of insights and knowledge in this area must be a core component of both computer science and information systems study programmes at colleges and universities. We conjecture that it will also be very relevant to translate many aspects to a secondary education context and incorporate them in secondary school IT courses.

Finally, although this paper repeatedly refers to curricula proposed by the Association for Computing Machinery [ACM, 2003, ACM, 2005], our detailed analysis and argumentation have been made in the context of Flemish education. Obviously, it will be very interesting to compare the approach to computer ethics in Flanders and Belgium with that in other regions and countries. This too, however, is left as a subject of future work.

\section{Acknowledgements}

Hilde De Gezelle, An De Vos, Leen Jacobs and Machteld Pensaert carefully read and commented upon draft versions of this paper. Next, the author wishes to thank Gerben Dierick for his invaluable knowledge and enthousiasm, in particular in the fields of recent technical developments in computer safety and encryption, as well as open and free software. The author is also indebted to these and other colleagues and students, at KHLeuven and KULeuven, for interesting discussions on computer ethics and/or education, as well as their contributions to his ongoing project to improve computer ethics teaching in secondary school. Finally, the author would like to explicitly acknowledge the members of IFIP WG9.2 as well as the "Ethicomp research community" for providing a stimulating and supporting international forum for learning and investigating about social and ethical issues in IT. 


\section{References}

Association for Computing Machinery (ACM) (2003), A Model Curriculum for K12 Computer Science: Final Report of the ACM K-12 Task Force Curriculum Committee, online at http://csta.acm.org/Curriculum/sub/k12final1022.pdf, accessed 13.04.2006.

Association for Computing Machinery (ACM) (2005), Computing Curricula 2005: The Overview Report, online at http:/www.acm.org/education/curricula, accessed 13.04.2006.

Bannier, S. and Onkelinx, P. (2005), Ethieksessie voor de derde graad TSO/ASO, Departement Lerarenopleiding, Katholieke Hogeschool Leuven (in Dutch), online at http://www.khleuven.be/publicaties/elfdegebod/downloads/secundair/Ethieksessie.pd f, accessed 13.04.2006.

Barroso, P. and Melara, G. (2004), Teaching of Computer Ethics at the State of California's Universities and Other Countries, in T.W. Bynum et al. (eds), Proceedings Ethicomp 2004, University of the Aegean, 106-115.

Bynum, T.W. and Rogerson, S. (eds) (2004), Computer Ethics and Professional Responsibility, Blackwell Publishing.

Cohen, M. (2000), Ethical Issues in Computer Based Learning, in G. Collste (ed), Ethics in the Age of Information Technology, Centre for Applied Ethics, Linköpings universitet, 195-211.

Creative Commons (CC) (2006), online at http://creativecommons.org/, accessed 13.04.2006.

Dawson, R.J. and Newman, I.A. (2002), Empowerment in IT Education, Journal of Information Technology Education, 1, 125-141.

Dierick, G. and Martens, B. (2006), Ethical and Social Issues in Information Technology (course notes, $5^{\text {th }}$ ed.), Katholieke Hogeschool Leuven.

European Computer Driving Licence Foundation (ECDLF) (2006), European Computer Driving Licence (ECDL), online at http://www.ecdl.com, accessed 13.04.2006.

Jefferies, P. and Stahl, B.C. (2005), Some Ethical Considerations Regarding the Relationship of E-Learning and Pedagogy, in G. Collste et al. (eds.), Looking Back to the Future, Proceedings of Ethicomp 2005, Linköping, Sweden, 12-15 September 2005, 12 pages. 
Johnson, D.G. (2001), Computer Ethics ( $3^{\text {rd }}$ ed.), Prentice Hall.

Kling, R., Rosenbaum, H. and Sawyer, S. (2005), Understanding and Communicating Social Informatics, Information Today.

Martens, B. (2000), Het elfde gebod, Beschouwingen over informatietechnologie, ethiek en samenleving, Acco (in Dutch).

Martens, B. (2001), Website on computer ethics, supporting [Martens, 2000], online at http://www.khleuven.be/publicaties/elfdegebod, accessed 13.04.2006.

Martens, B. (2003a), Ethiek en veiligheid in de computerklas, in D. Gombeir et al. (eds.), ICT en onderwijsvernieuwing, Wolters-Plantyn, 24 pages (in Dutch).

Martens, B. (2003b), Informatica op school en in de lerarenopleiding, in D. Gombeir et al. (eds.), ICT en onderwijsvernieuwing, Wolters-Plantyn, 22 pages (in Dutch).

Martens, B. (2004), Ethische en maatschappelijke vraagstukken in de informatica (educational supplement with [Martens, 2000], $5^{\text {th }}$ ed.), Katholieke Hogeschool Leuven (in Dutch), online at http://www.khleuven.be/publicaties/elfdegebod/downloads/onderwijsbijlage/Onderw ijsbijlage.pdf accessed 13.04.2006.

Martens, B. (2005), Computer Ethics in Secondary School and Teacher Training, in G. Collste et al. (eds.), Looking Back to the Future,

Proceedings of Ethicomp 2005, Linköping, Sweden, 12-15 September 2005, 10 pages.

Rathenau Instituut en Sociaal Cultureel Planbureau (RISCP) (2006), Jaarboek ICT \& samenleving: de digitale generatie, Boom (in Dutch).

Stahl, B.C., Wood, C. and Howley, R. (2004), Teaching Professional Issues in Computing through the Development of a Student Code of Conduct, in T.W. Bynum et al. (eds), Proceedings Ethicomp 2004, University of the Aegean, 812-825.

Thompson, J.B. and Edwards, H.M. (2004), Providing Graduate Computing Students with an Appreciation of Appropriate Ethical, Professional and Legal Issues, in T.W. Bynum et al. (eds), Proceedings Ethicomp 2004, University of the Aegean, 839-853.

Vlaams Verbond van het Katholiek Secundair Onderwijs (VVKSO) (2003), Leerplan secundair onderwijs: Informatica, tweede graad ASO, KSO, TSO (in Dutch), online at $\mathrm{http}: / /$ ond.vvkso-ict.com/leerplannen/doc/Informatica-2003-028.pdf, accessed 13.04.2006.

Vlaams Verbond van het Katholiek Secundair Onderwijs (VVKSO) (2005), Synthesenota van de Ronde Tafel Informatica (in Dutch), online at http://ond.vvksoict.com/vvksosites/download/informatica/SyntNota.pdf, accessed 13.04.2006. 